\title{
The Use of Bolted U-Link Swimmer Bars in the Reinforced Concrete Beams
}

\author{
Moayyad M. Al-Nasra, Naiem M. Asha \\ ${ }^{1}$ (Department of Engineering Technology, West Virginia University \\ Institute of Technology, Montgomery, WV 25136, USA) \\ ${ }^{2}$ (Department of Civil Engineering, University of Jordan, Amman, Jordan
}

\begin{abstract}
Shear failure in reinforced concrete beams is one of the most undesirable modes of failure due to its rapid progression. This sudden type of failure made it necessary to explore more effective ways to design these beams for shear. The reinforced concrete beams show different behavior at the failure stage in shear compare to the bending, which is considered to be unsafe mode of failure. The diagonal cracks that develop due to excess shear forces are considerably wider than the flexural cracks. The cost and safety of shear reinforcement in reinforced concrete beams led to the study of other alternatives. Swimmer bar system is a new type of shear reinforcement. It is a small inclined bars, with its both ends bent horizontally for a short distance and welded or bolted to both top and bottom flexural steel reinforcement. Regardless of the number of swimmer bars used in each inclined plane, the swimmer bars form plane-crack interceptor system instead of bar-crack interceptor system when stirrups are used. Several reinforced concrete beams were carefully prepared and tested in the lab. The results of these tests will be presented and discussed. The deflection of each beam is also measured at incrementally increased applied load. The propagation of shear cracks was also closely monitored.
\end{abstract}

Keywords: - Swimmer bar, Deflection, Shear, Crack, Stirrup

\section{INTRODUCTION}

The reinforced concrete beams are designed primarily for flexural strength and shear strength. Beams are structural members used to carry loads primarily by internal moments and shears. In the design of a reinforced concrete member, flexure is usually considered first, leading to the size of the section and the arrangement of reinforcement to provide the necessary resistance for moments. For safety reasons, limits are placed on the amounts of flexural reinforcement to ensure ductile type of failure. Beams are then designed for shear. Since shear failure is frequently sudden with little or no advanced warning, the design for shear must ensure that the shear strength for every member in the structure exceeds the flexural strength. The shear failure mechanism varies depending upon the cross-sectional dimensions, the geometry, the types of loading, and the properties of the member.

Reinforced concrete beams must have an adequate safety margin against bending and shear forces, so that it will perform effectively during its service life. At the ultimate limit state, the combined effects of bending and shear may exceed the resistance capacity of the beam causing tensile cracks. The shear failure is difficult to predict accurately despite extensive experimental research. Retrofitting of reinforced concrete beams with multiple shear cracks is not considered an option [1].

Diagonal cracks are the main mode of shear failure in reinforced concrete beams located near the supports and caused by excess applied shear forces. Beams fail immediately upon formation of critical cracks in the high-shear region near the beam supports. Whenever the value of actual shear stress exceeds the permissible shear stress of the concrete used, the shear reinforcement must be provided. The purpose of shear reinforcement is to prevent failure in shear, and to increase beam ductility and subsequently the likelihood of sudden failure will be reduced.

Normally, the inclined shear cracks start at the middle height of the beam near support at approximately 450 and extend toward the compression zone. Any form of effectively anchored reinforcement that intersects these diagonal cracks will be able to resist the shear forces to a certain extent. In practice, shear reinforcement is provided in three forms; stirrups, inclined bent-up bars and combination system of stirrups and bent-up bars.

In reinforced concrete building construction, stirrups are most commonly used as shear reinforcement, for their simplicity in fabrication and installation. Stirrups are spaced closely at the high shear region. Congestion near the support of the reinforced concrete beams due to the presence of the closely spaced stirrups increase the cost and time required for installation. 
Bent up bars are also used along with stirrups in the past to carry some of the applied shear forces. In case where all the tensile reinforcement is not needed to resist bending moment, some of the tensile bars where bent-up in the region of high shear to form the inclined legs of shear reinforcement. The use of bent-up bars is not preferred nowadays. Due to difficulties in construction, bent-up bars are rarely used. In beams with small number of bars provided, the bent-up bar system is not suitable due to insufficient amount of straight bars left to be extended to the support as required by the code of practice.

In this study, three reinforced concrete beams were tested using the new shear reinforcement swimmer bar system and the traditional stirrups system. Several shapes of swimmer bars are used to study the effect of swimmer bar configuration on the shear load carrying capacity of the beams. Only three beams will be presented in this study. The first beam, BC, is used as a reference control beam where stirrups are used as shear reinforcement. The other two beams were reinforced by swimmer bars. Beam, BW is the beam which is reinforced by two swimmer bars welded to the longitudinal top and bottom bars. Beam, BU is the beam which is reinforced by U-link bars which are bolted to the top and bottom longitudinal bars along with two swimmer bars. Extra stirrups were used to make sure that beam will fail by shear in the swimmer bars side. In this investigation, all of the beams are supposed to fail solely in shear, so adequate amount of tension reinforcement were provided to give sufficient bending moment strength. This study aims at investigating a new approach of design of shear reinforcement through the use of swimmer bars provided in the high shear region. The main advantages of this type of shear reinforcement system are: flexibility, simplicity, efficiency, and speed of construction.

Piyamahant showed that the existing reinforced concrete structures should have stirrup reinforcement equal to the minimum requirement specified the code. The theoretical analysis shows that the amount of stirrup of $0.2 \%$ is appropriate. The paper concluded that small amount of web reinforcement is sufficient to improve the shear carrying capacity. The study focused on the applicability of the superposition method that used in predicting shear carrying capacity of reinforced concrete beam with a small amount of web reinforcement at the shear span ratio of 3. Also the failure mechanisms were considered when small amount of stirrup used [2].

Sneed, and Julio discussed the results of experimental research performed to test the hypothesis that the effective depth does not influence the shear strength of reinforced concrete flexural members that do not contain web reinforcement [3]. The results of eight simply supported reinforced concrete beam tests without shear and skin reinforcement were investigated. The beams were designed such that the effective depth is the variable while the values of other traditionally-considered parameters proven to influence the shear strength (such as the compressive strength of concrete, longitudinal reinforcement ratio, shear span-to-depth ratio, and maximum aggregate size) were held constant. The values selected for the parameters held constant were chosen in an attempt to minimize the concrete shear strength.

Noor presented several results of experimental investigation on six reinforced concrete beams in which their structural behavior in shear was studied [4]. The research conducted was about the use of additional horizontal and independent bent- up bars to increase the beam resistance against shear forces. The main objectives of that study were studying the effectiveness of adding horizontal bars on shear strength in rectangular beams, the effectiveness of shear reinforcement, and determining the optimum amount of both types of shear reinforcement to achieve a shear capacity similar to that of a normal links system. From experimental investigation of the system it was found that, the use of independent horizontal and bent-up bars as shear reinforcement were stronger than conventional shear reinforcement system.

\section{SWIMMER BARS}

A swimmer bar is a small inclined bar, with its both ends bent horizontally for a short distance, welded or bolted at the top and the bottom of the longitudinal bars. There are three major standard shapes; single swimmers, rectangular shape, and rectangular shape with cross bracings. Several additions to these standard shapes can be explored, such as addition of horizontal stiffener bars in the rectangular shapes, dividing the large rectangle horizontally into smaller rectangles. Additional swimmer bars can also be used. By adding one more swimmer bar to the rectangular shape, the large rectangular shape will be divided vertically into two rectangles. Addition of two more swimmer bars will divide the large rectangle vertically into four small rectangles. A combination of horizontal bars and additional swimmer bars may also be explored. This swimmer bar system is integrated fully with the longitudinal steel bars. Several options of the swimmer bar systems are used in order to improve the shear performance of the reinforced concrete beams, reduce the amount of cracks, reduce the width and the length of cracks and reduce overall beam deflection. Different bar diameters can be used in order to add stiffness to the steel cage, and increase shear strength of the reinforced concrete beam.

\section{ACI CODE PROVISION FOR SHEAR DESIGN}

According to the ACI Code [5], the design of beams for shear is to be based on the following relation: $V_{u} \leq \propto V_{n}$ 
Where: $V_{u}$ is the total shear force applied at a given section of the beam due to factored loads and $V_{n}=V_{c}+V_{s}$ is the nominal shear strength, equal to the sum of the contribution of the concrete and the web steel if present. Thus for vertical stirrups

$V_{u} \leq \varrho V_{c}+\frac{\rho A_{v} f_{y t^{d}}}{s}$

and for inclined bars

$V_{u} \leq \omega V_{c}+\frac{\rho A_{v} f_{y t} d(\sin \alpha+\cos \alpha)}{s}$

Where: $A_{v}$ is the area of one stirrup, $\alpha$ is the angle of the stirrup with the horizontal, and $S$ is the stirrup spacing.

The nominal shear strength contribution of the concrete (including the contributions from aggregate interlock, dowel action of the main reinforcing bars, and that of the un-cracked concrete) can be simplified as shown in Eq. 4.

$$
V_{\mathrm{c}}=0.17 \lambda \sqrt{f_{\mathrm{c}}^{\mathrm{c}}} b_{\mathrm{w}} d
$$

Where: $b_{w}$ and $d$ are the section dimensions, and for normal weight concrete, $\lambda=1.0$. This simplified formula is permitted by the ACI code expressed in metric units [6].

\section{TESTED BEAMS}

This study focused on investigating the shear strength of three different types of reinforced concrete beams; beam reinforced with regular stirrups, beam reinforced with welded swimmer bars, and beam reinforced with U-link bolted swimmer bar. All specimens were of the same size and reinforced with identical amount of longitudinal steel. The amount of longitudinal steel used in this study is, by design, selected to make sure that the failure will be dictated only by shear and not by bending. The beams were tested to fail due to two point loads by shear given the ratio of a shear span to effective depth of 2.5. The compressive strength of concrete is measured according to ASTM C 192-57. Nine concrete samples were prepared. The compressive strength of concrete is measured at the $28^{\text {th }}$ day. The concrete compressive strength results range between $26.7 \mathrm{~N} / \mathrm{mm}^{2}$ to $27.2 \mathrm{~N} . \mathrm{mm}^{2}$. The variables in these specimens are the shear reinforcement systems.

Three reinforced concrete beams were prepared for the test, BS which the beam with regular stirrups, BW which is the beam with welded swimmer bars, and BU which the beam with U-link bolted swimmer bars. All of the beams are of the same dimension $2000 \mathrm{~mm}$ length, $200 \mathrm{~mm}$ width and $250 \mathrm{~mm}$ depth. The effective length was also kept at constant value of $1800 \mathrm{~mm}$. Summary of shear reinforcement system for each specimen is given in Table 1. All tested beams were designed with $3 \varnothing 14$ top steel and $4 \varnothing 16$ bottom steel reinforcement. The reference beam, BC, was designed with $10 \varnothing 8 \mathrm{~mm}$ at $600 \mathrm{~mm}$ spacing vertical stirrup at either side without any stirrups at the high moment zone between the two concentrated loads. New type of shear reinforcement called welded swimmer bars, BW, and U-link bolted swimmer bars, BU were used in this experiment. The swimmer bars were used as independent bent-up bars and welded/bolted with $\varnothing 10 \mathrm{~mm}$ steel piece. The swimmer bars used in beams BW, BU are of $\varnothing 10 \mathrm{~mm}$ and spaced of $275 \mathrm{~mm}$ apart as shown in Fig. (1). The weight of each steel cage is also listed in Table 1. The weight of each steel cage is almost the same.

Fig. (2) shows the steel cage used in beam BW, the welded swimmer bars, and Fig. (3) shows the steel cage used in BU, the U-link bolted swimmer bars. The weights of these two cages were intentionally designed to be very close in numbers. The erection and assembling time of the bolted beam is relatively less than the erection and assembling time of the welded beam.

Table 1: Summary of steel reinforcement used in the tested beams

\begin{tabular}{|l|l|l|l|}
\hline $\begin{array}{l}\text { Beam } \\
\text { No. }\end{array}$ & $\begin{array}{l}\text { Shear Reinforcement } \\
\text { Vertical Bent-up } \\
\text { stirrup Bars }\end{array} \quad \begin{array}{l}\text { Steel Cage } \\
\text { Weight } \\
\text { (N) }\end{array}$ \\
\hline BC & $\begin{array}{l}10 \varnothing 8 \mathrm{~mm} \mathrm{@} \mathrm{600mm} \mathrm{at} \\
\text { shear sides }\end{array}$ & 255 \\
\hline BW & - & Two welded swimmers, $\varnothing 10 \mathrm{~mm} @ 275 \mathrm{~mm}$ & 250 \\
\hline B3 & - & Two U-link Bolted swimmers, $\varnothing 10 \mathrm{~mm} @ 275 \mathrm{~mm}$ & 255 \\
\hline
\end{tabular}




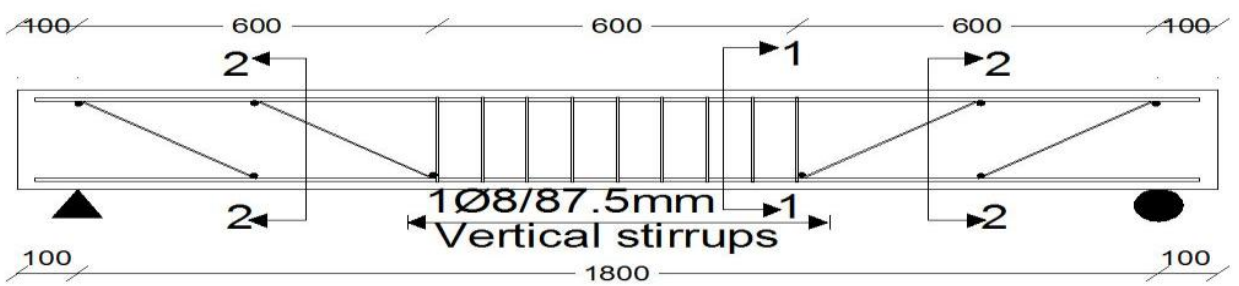

$3 \varnothing 14$ Top bars

$4 \varnothing 16$ Bottom bars

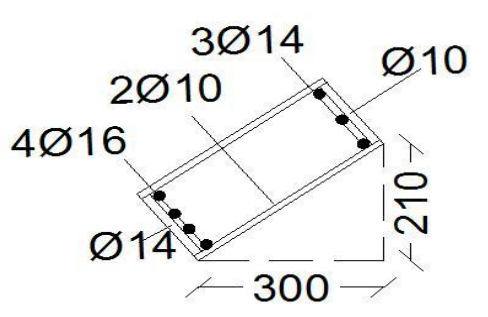

$3 \varnothing 14$

(Two swimmer bars $/ 275.0 \mathrm{~mm}$ )

CROSS SEC2-2

CROSS SEC $1-1$

Figure 1: Reinforcement details of BW, and BU

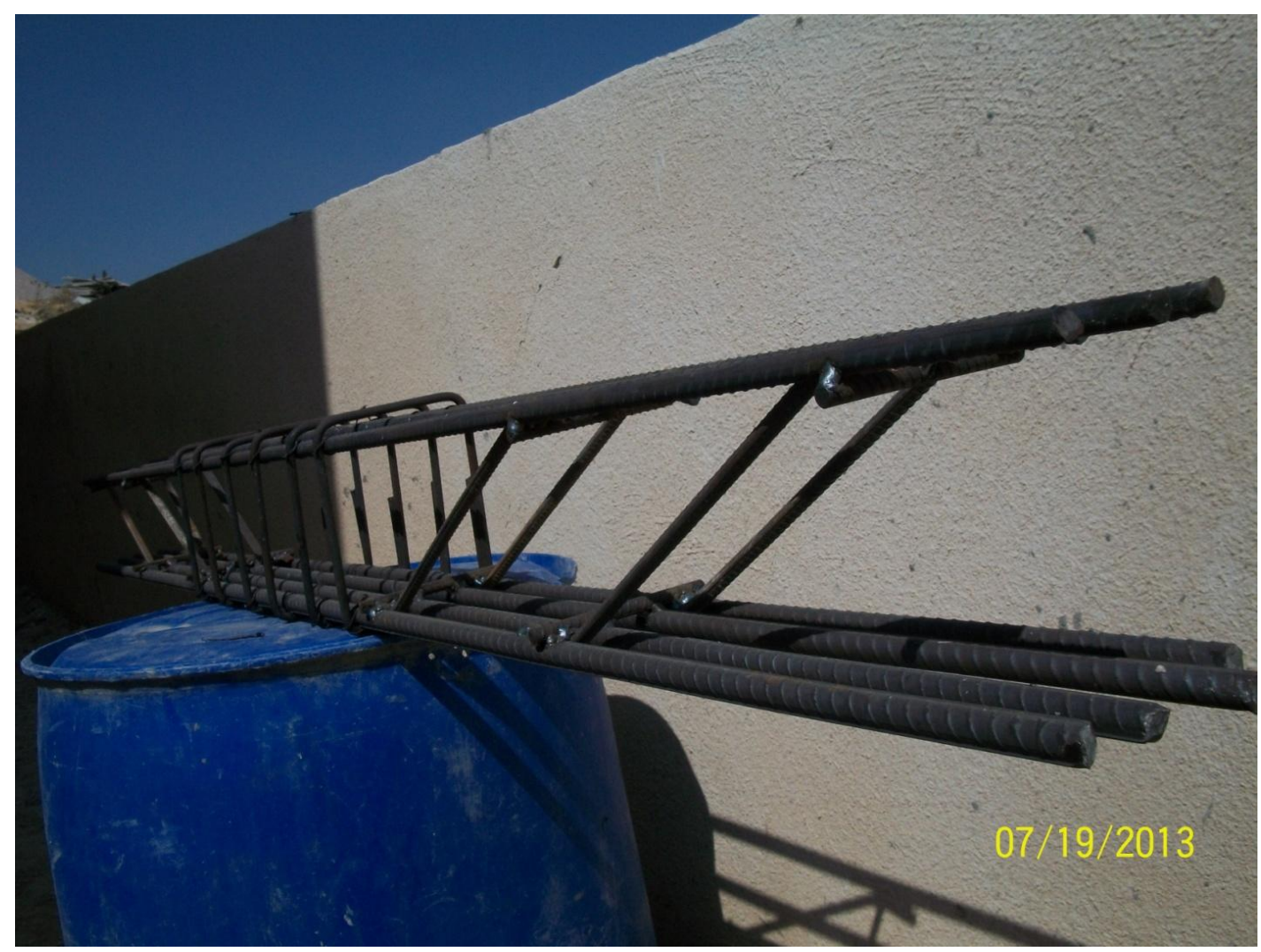

Figure 2: Steel cage reinforcement of the beam BW, welded swimmer bars. 


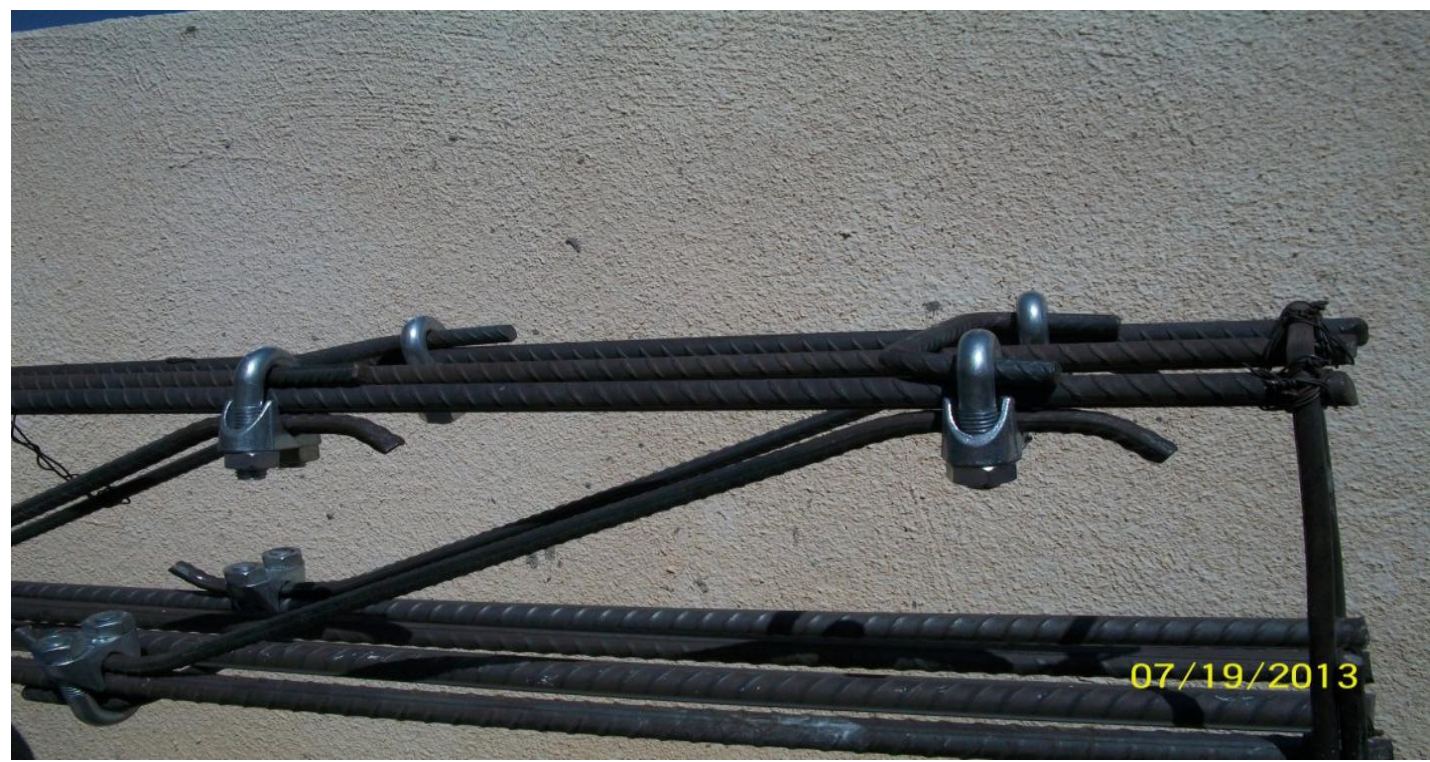

Figure 3: Steel cage reinforcement of the beam, BU, U-link bolted swimmer bars.

\section{TEST PROCEDURE}

Prior to testing, the surface of the specimens was painted with white emulsion for the purpose of making the cracks more visible and easy to track. At age 28 days reinforced concrete beams were prepared for testing. Marking lines were used to show the location of the point loads, supports and the mid-span of the beam in order to make it easier to install the beams on the testing machine. The test was carried out with the specimen placed horizontally in a simple loading arrangement. The beams were supported by solid round steel on their two edges that can be considered as simply supported beam member. All the beams were designed to ensure the beams will only fail in shear rather than in flexure.

To ensure that shear cracks will occur near the support, two point loads were applied symmetrically to the beam with $\mathrm{a}_{\mathrm{v}}$ less than $2.5 \mathrm{~d}$. In this testing, $\mathrm{a}_{\mathrm{v}} \approx 550 \mathrm{~mm}$, where $\mathrm{a}_{\mathrm{v}}$ is shear span ( the distance from the point of the applied load to the support), and $d$ is the effective depth of a beam.

A loading jack was placed at the mid-span position above the beam. The load was applied by jacking the beam against the rig base member at a constant rate until the ultimate load capacity of the beam was reached. A universal column section was used to transfer the load to the beam at two point loads via transfer girder. A reasonable time interval was allowed in between each $20.0 \mathrm{kN}$ load increments for measuring deflections, marking cracks, measuring the shear reinforcement strain and recording the ultimate load. Each beam took about two hours to complete the test. The cracks were monitored at each load increment. Fig. (4) shows the experimental set up

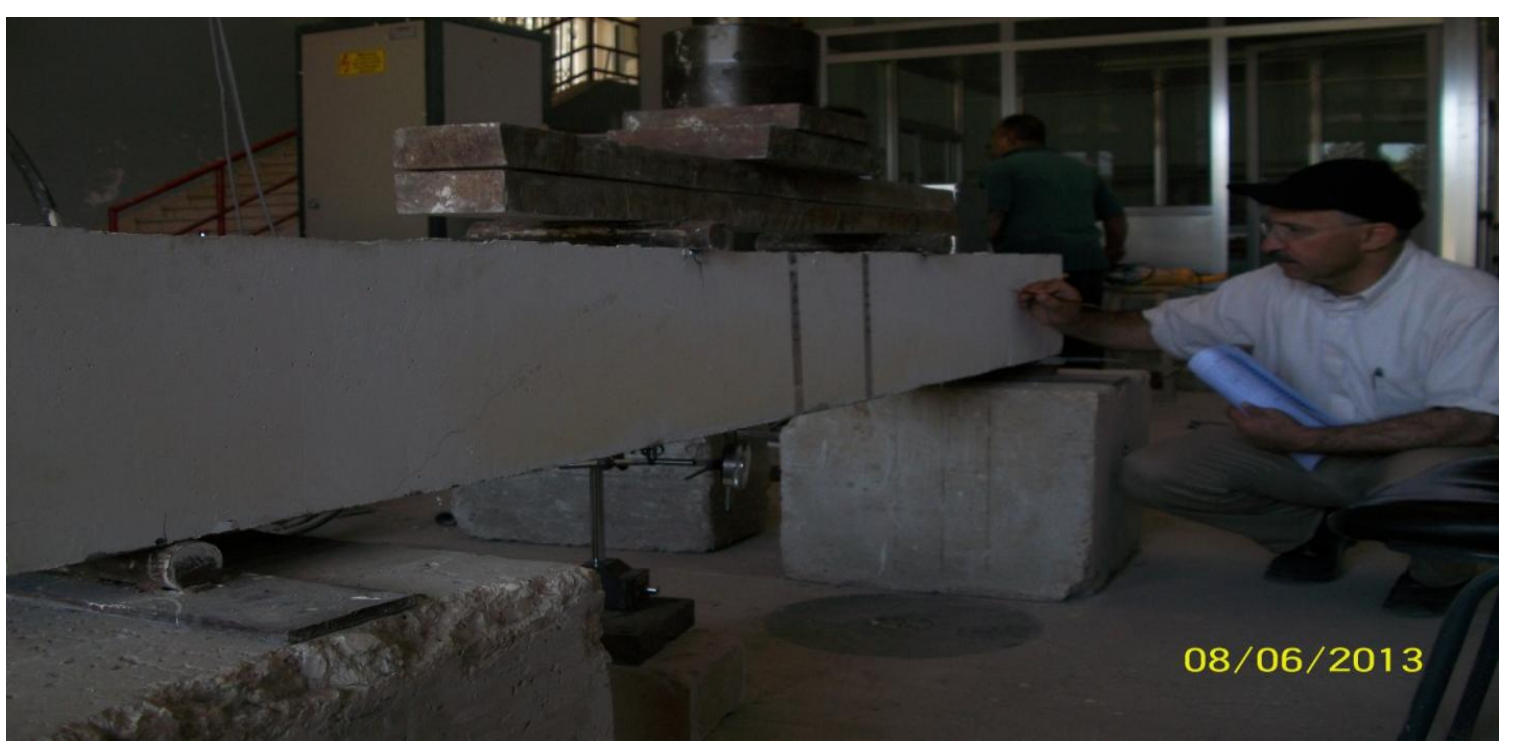

Figure 4: Experimental set up and crack monitoring 
VI. TEST RESULTS

The beam BC showed typical mode of failure by shear at the ultimate load of $180 \mathrm{kN}$. Beam BW and BU showed quite similar mode of failure. Several micro-cracks appeared early in the loading process. These cracks were extended and widened as the load increases. These cracks became visible at the load of about 100 $\mathrm{kN}$. As the loading was increased more cracks developed. The cracks migrate towards the top corners as the load increases. More flexure cracks appeared at a load of $100 \mathrm{kN}$ in the moment region. These cracks increased by increasing the applied load, and new cracks developed but at relatively slower paste. Fig. (5) shows the beam, BU, at failure stage.

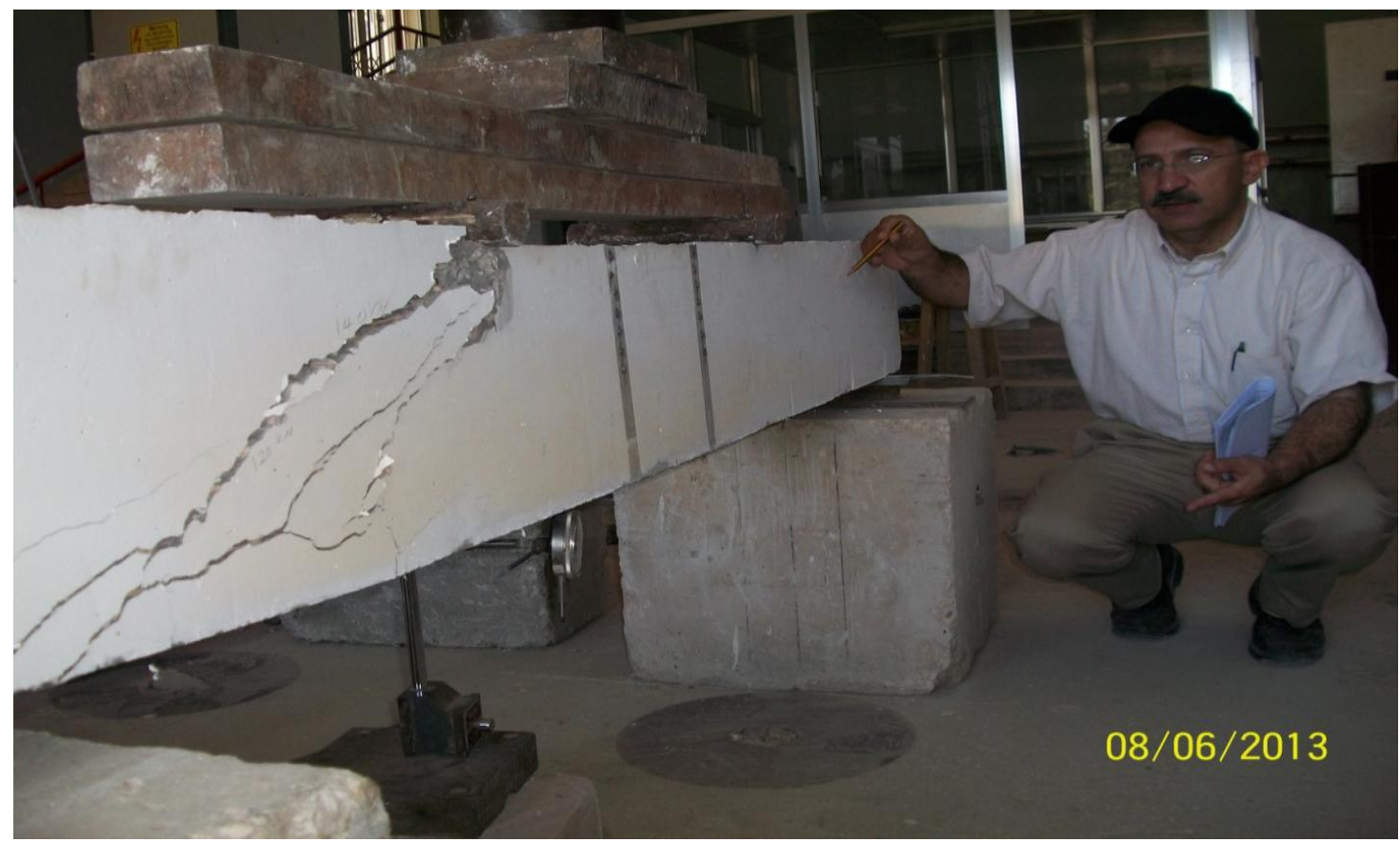

Figure 5: Beam BU at failure stage.

Fig. (6) shows the maximum applied load the beam carried just before failure. All of the tested beams in this study failed by shear. The beam of welded swimmer bars exhibit similar strength as the beam of U-link bolted swimmer bars. This proves that welding can be avoided when dealing with swimmer bars. The welding process is of a major concern when it comes to the quality control of the welds.

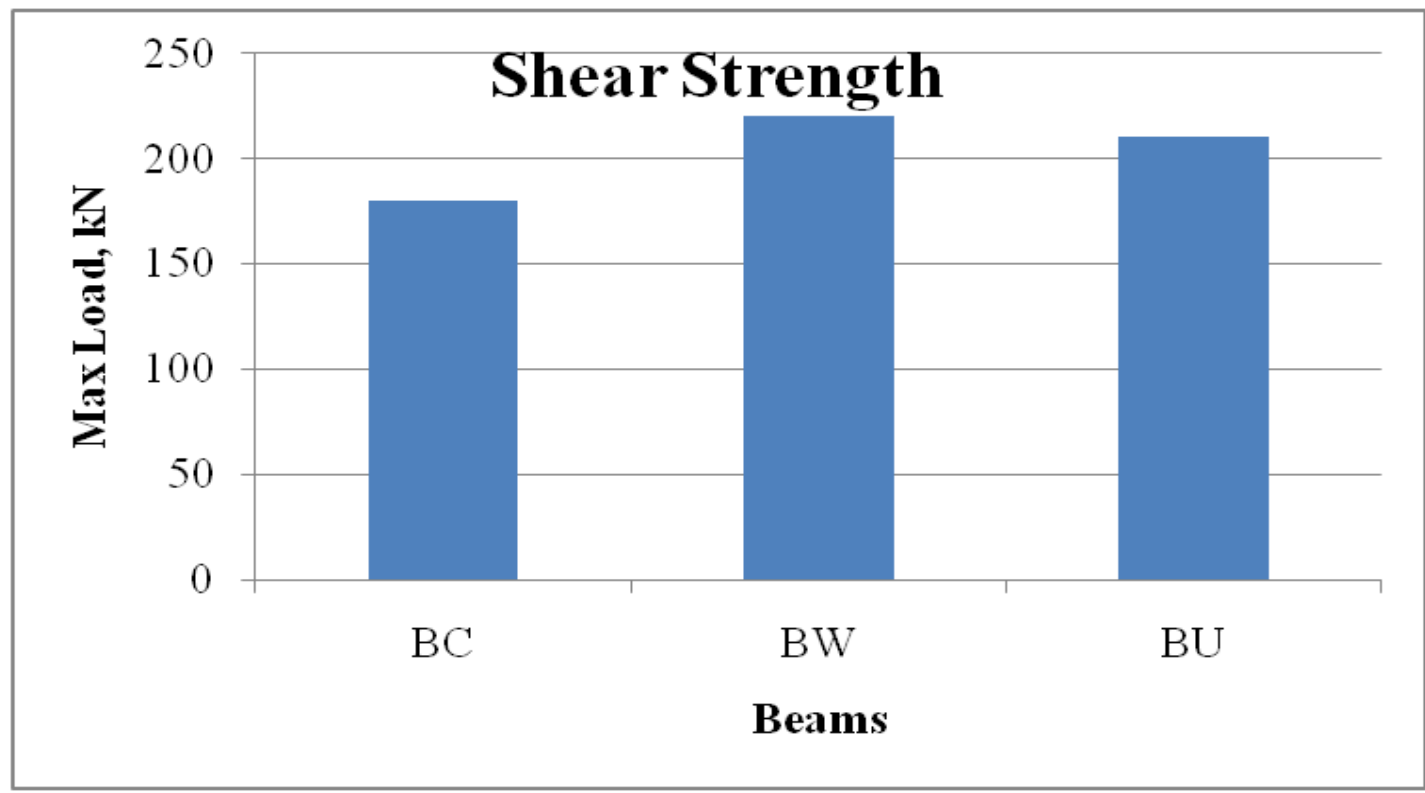

Figure 6: Shear strength of the three tested beams 
Fig. (7) shows the maximum recorded deflection just before failure. No major difference in the load deflection relationship was observed in the tested beams. Beams deflection increased with the increase in load up to the failure load.

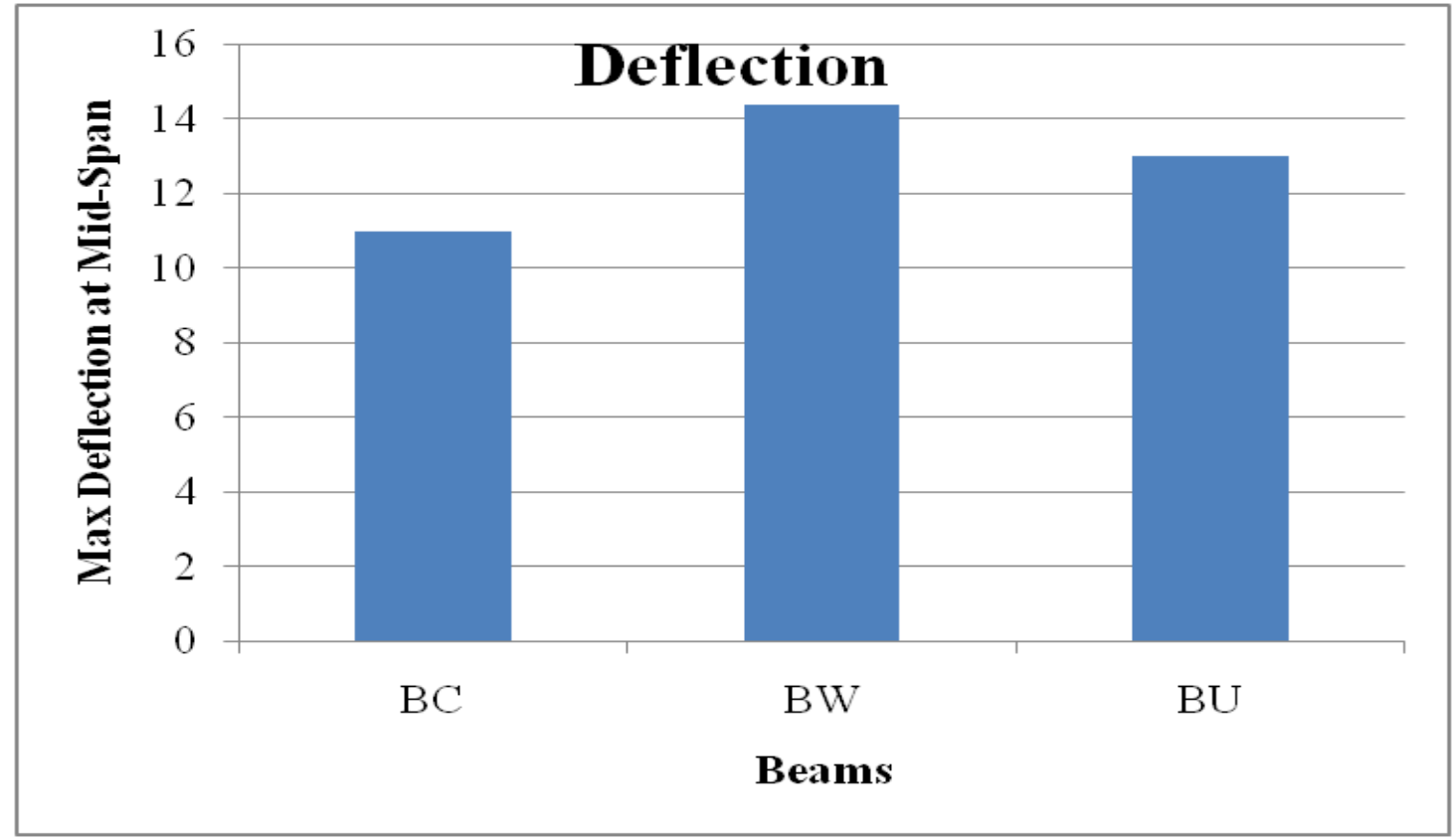

Figure 7: Maximum deflection at mid-span of tested beams just before failure.

\section{CONCLUSION}

This study presented a new type of shear reinforcement called swimmer bar system joined with the longitudinal bars by using either welds or bolts. There is improvement in shear strength of reinforced concrete beams by using swimmer bars in general. The bolted swimmers bars through U-links showed similar results as the welded. The width and length of the cracks were observed to be less using swimmer bars compared to the traditional stirrups system. It was observed that the ductility of beams reinforced with swimmer bars improved slightly compared with the beams reinforced with the traditional stirrup system.

VIII.

REFERENCES

[1] Al-Nasra, M.M., and Wang, L.R.L., 1994, Parametric Study of Slab-On-Grade Problems: Due to Initial Warping and Point Loads. ACI Structural Journal, Vol. 91 No. 2.http://www.concrete.org /PUBS/JOURNALS/OLJDetails.asp?Home=SJ\&ID=4596

[2] Piyamahant, (2002), Shear behavior of reinforced concrete beams with small amount of web reinforcement, M. Eng. Dissertation, Kochi University of Technology, Japan

[3] Lesley H. Sneed and Julio A. 2008, Effect of Depth on the Shear Strength of Concrete Beams without Shear Reinforcement, USA Portland and cement Association. http://www.cement.org/exec2/11-0308.htm

[4] Noor Hamid (2005). The Use of Horizontal and Inclined Bars as Shear Reinforcement , Master Thesis, University of Technology, Malaysia, http://sunzi.lib.hku.hk/hkuto/record/B26643352.

[5] ACI 318-11, 2011. Building Code Requirements for Structural Concrete Commentary. http://www.concrete.org/pubs/newpubs/31811.htm

[6] Edward G.Nawy, 2009. Reinforced Concrete: A Fundamental Approach, Prentice Hall International, US, PP 120-315, ISBN 0132417030, 9780132417037 